\title{
Is visual lexical access based on phonological codes? Evidence from a picture-word interference task
}

\author{
MARKUS F. DAMIAN and RANDI C. MARTIN \\ Rice University, Houston, Texas
}

\begin{abstract}
The claim that lexical access for visual words is mandatorily mediated by their phonological codes was investigated. Ninety-six subjects performed timed naming responses to pictures while instructed to ignore printed words superimposed on the pictures. Distractor words were either semantically related to the picture label or were homophones of a word semantically related to the picture name. On the basis of the claim that homophones initially activate multiple semantic codes, we hypothesized that the homophone and semantic distractors would yield comparable interference. Picture-word stimulus onset asynchrony (SOA) was varied between subjects as 0 or $+100 \mathrm{msec}$. For an SOA of $0 \mathrm{msec}$, semantic interference, but no effect from the homophones, was obtained. For an SOA of $+100 \mathrm{msec}$, no effect was obtained in either condition. In combination, these findings indicate a limited role of phonological codes in visual lexical access. It is suggested that the role of phonology in written word identification may vary dependent on procedure and utility to the task.
\end{abstract}

The last 25 years have seen extensive research on the role of phonological codes in written-word identification. A position that can be dated back to the 1970 s claims that visual lexical access is essentially and mandatorily mediated by phonology. Such findings as Rubenstein, Lewis, and Rubenstein's (1971), indicating that pseudohomophones (CLOKE) took longer to reject in a visual lexical decision task than did nonwords that were not pseudohomophones (TORS), were taken to suggest that a printed word activated its phonological codes before accessing the lexical entry. Such accounts generally assume that homophones initially activate lexical entries corresponding to two or more meanings of the homophone. To resolve these ambiguities, a fast-acting spelling-check procedure is hypothesized that verifies the orthographic identity of the target word and eliminates activation of the inappropriate lexical entry (Lesch \& Pollatsek, 1993; Lukatela \& Turvey, 1994b; Rubenstein et al., 1971; Van Orden, 1987).

The primacy of phonological codes in word recognition has been challenged by a number of experimental studies in which researchers have failed to consistently obtain phonological effects in word processing (e.g., Davelaar, Coltheart, Besner, \& Jonasson, 1978; Hawkins, Reicher, Rogers, \& Peterson, 1976; Martin, 1982; McQuade, 1981). Furthermore, neuropsychological evidence suggests the existence of a direct visual route to semantics in addition to a grapheme-to-phoneme conversion route. For instance, deep dyslexics appear to have an intact direct route but

Preparation of this article was supported in part by National Institutes of Health Grant DC 00218 to Rice University. Correspondence should be addressed to R. C. Martin, Psychology Department, Rice University, P.O. Box 1892, Houston, TX 77251 (e-mail: rmartin@rice.edu). an impaired sublexical route, resulting in the occurrence of semantic, but not phonologically based, errors in reading (Coltheart, 1980; see also Coltheart \& Coltheart, 1997, for more recent neuropsychological evidence in regard to this issue). Dual-route models of reading attempt to account for these findings by proposing the existence of a direct lexical route in addition to the sublexical phonological procedure. The two routes are hypothesized to engage in a "horse race" (Meyer, Schvaneveldt, \& Ruddy, 1974), to act in combination (Coltheart, 1980), or to be under the subject's strategic control in response to task demands (Baluch \& Besner, 1991; Davelaar et al., 1978; Hawkins et al., 1976; Hudson \& Bergman, 1985; McQuade, 1981; Milota, Widau, McMickell, Juola, \& Simpson, 1997; Tabossi \& Laghi, 1992).

The claim that lexical access is mandatorily mediated by phonological codes has recently been revived, prompted by early phonological effects that have been obtained in a number of new paradigms - for example, in semantic categorization tasks (Van Orden, 1987; Van Orden, Johnston, \& Hale, 1988), in backward visual masking (Perfetti \& Bell, 1991; Perfetti, Bell, \& Delaney, 1988), and in the priming of naming responses (Lukatela \& Turvey, 1994a, 1994b). As a result, some researchers again propose the universal importance of speech recoding in visual lexical access. For instance, Lukatela and Turvey (1994b), in a recent paper, conclude that a word's phonology constitutes "the initial and primary code by which a word accesses its representation in the internal lexicon. As to the role of a word's orthographic structure, these results suggest that it figures most significantly in processes that reduce the noise in the lexicon following activation by the word's phonological code" (p. 333).

In summary, existing evidence indicates a crucial role of phonology in visual lexical access in some studies and 
paradigms, but not in others. Thus, some caution should be exerted in forwarding strong claims about the primacy of phonological codes. The present study contributes evidence to this issue by employing the picture-word interference task introduced by Rosinski, Golinkoff, and Kukish (1975), in which subjects are asked to name a picture and to ignore a distractor word superimposed on the picture. In this procedure, semantic overlap between distractor word and picture label (picture, APPLE; distractor, PEAR) results in prolonged naming latencies relative to an unrelated condition (picture, APPLE; distractor, FOOT), whereas if distractor words are graphemically or phonologically related to the picture name (picture, APPLE; distractor, APRON-Lupker, 1982) responses are facilitated. By varying the stimulus onset asynchrony (SOA) between picture and word, estimates of the time course of semantic and graphemic/phonological activation can be obtained (cf. Glaser \& Düngelhoff, 1984). Within this paradigm, Rayner and Posnansky (1978) investigated the effect of homophonic distractors. The authors showed that nonwords that preserved the pronunciation of the picture label (byrd) yielded more facilitation on the naming of the target (BIRD) than did nonwords that preserved word shape but not pronunciation (baid). This was interpreted as indicating phonemic recoding of the distractor word. Rather than examine the facilitative effects of distractors homophonic to the picture label, in the present study we focused on possible semantic interference effects caused by homophones. The effect of distractor words that were semantic coordinates of the picture label (picture, APPLE; distractor, PEAR) were compared with the effect of words that were homophones of semantic coordinates to the picture label (picture, APPLE; distractor, PAIR). The basic semantic interference effect has been shown to center on a picture-word SOA of 0 msec (Glaser \& Düngelhoff, 1984; Starreveld \& La Heij, 1996). This is normally taken as evidence that the distractor words have accessed their lexical and semantic representations. With regard to the homophone distractors, accounts favoring the primacy of phonological codes in lexical access would predict that these words could activate their own meaning and that of their homophones (e.g., PAIR should activate the meanings of PAIR and PEAR). The time course of this activation should correspond to the time course of activation of semantic representations for nonhomophonous words. Thus, PAIR should demonstrate at least some interference with the naming of APPLE at the same SOA at which PEAR interferes with the naming of APPLE. The absence of such an effect would violate a central prediction of theories postulating phonologically mediated semantic access. Note that the procedure above has advantages over the one employed by Rayner and Posnansky (1978), because (1) the hypothesized effect is interfering and thus should be immune to strategies, and (2) the distractor words are graphemically and orthographically dissimilar to the picture label and therefore cannot yield articulatory priming, which was hypothesized by Rayner and Posnanksy to be a possible origin of their homophone facilitation effect (p. 79).
The fact that an SOA of $0 \mathrm{msec}$ typically results in robust semantic interference suggests that words and pictures show a roughly comparable time course of semantic activation. This conclusion, however, seems to be in conflict with studies (e.g., Potter \& Faulconer, 1975) showing shorter response latencies for pictures than for words in tasks that require semantic categorization. The faster times for pictures suggests that pictures gain privileged access to conceptual codes. This interpretation of the picture superiority effect in categorization has been challenged, however: Snodgrass and McCullough (1986) have forwarded a "visual similarity hypothesis" that claims that pictures typically can be classified into superordinate categories not only by means of their semantic codes but also by the use of visual surface similarity within a category. This assumption would explain why picture categorization typically shows shorter response latencies than word categorization whereas results from the pictureword interference paradigm suggest similar time courses of semantic activation for pictures and words. It should be noted, however, that studies that have assessed the time course of semantic interference in the picture-word interference procedure have not obtained wholly consistent findings. For instance, Glaser and Düngelhoff's (1984) study indicated substantial interference at $\mathrm{SOA}=0 \mathrm{msec}$ $(-84 \mathrm{msec})$ and $\mathrm{SOA}=+100 \mathrm{msec}(-81 \mathrm{msec})$. In contrast, a recent study by Starreveldt and La Heij (1996) showed maximum interference at $\mathrm{SOA}=-100 \mathrm{msec}$ $(-37 \mathrm{msec})$ and reduced interference at SOA $=0 \mathrm{msec}$ $(-27 \mathrm{msec})$. These findings suggest that certain-possibly perceptual-variables that are not yet well understood influence the relative time course of picture and word processing. However, on the basis of the findings in the literature, we predicted that an SOA of 0 msec would demonstrate activation of the correct meaning by showing interference from related distractor words.

The theory that visual lexical access is mandatorily mediated by phonological codes assumes that homophones activate multiple meanings both consistent and inconsistent with their spelling. Activation of the orthographically inconsistent meaning is claimed to occur simultaneously with the activation of the orthographically consistent one (e.g., Van Orden et al., 1988). Suppose that at the 0msec SOA interference is found for the semantically related word but not for the homophone. Proponents of the phonological coding theory of lexical access might claim that the homophonic meaning has already been eliminated at that SOA. The spelling-check procedure normally forwarded by these theorists is assumed to rapidly reduce semantic activation down to the correct meaning. For instance, in a series of experiments by Lukatela and Turvey (1994b) subjects were asked to name target words (FROG) that were preceded by either associatively related words (TOAD) or words that were homophonous to the associate (TOWED). At SOAs of $100 \mathrm{msec}$ and below, the words homophonous to the targets and those associatively related to the targets showed equal amounts of priming. For an SOA of $250 \mathrm{msec}$, only related items primed the targets. These findings presum- 
ably demonstrated that the cleanup procedure had successfully eliminated the lexical ambiguity, and appear to suggest that the proposed mechanism functions rather rapidly. For the present experiment, we predicted that an SOA of 0 msec would produce interference from semantically related distractor words. However, the possibility arises that this SOA measures a stage of distractor-word processing in which the activation of multiple meanings has already been reduced to the correct one. Therefore, it would be important to employ a further condition that looks at earlier stages of visual word recognition relative to processing of the picture - that is, at positive SOAs. Figure 1 depicts this possibility; case A demonstrates a simultaneous picture-word onset (SOA of $0 \mathrm{msec}$ ), whereas case B shows a positive SOA in which the distractor is displayed after picture onset. To investigate the possibility that an SOA of 0 msec misses the phase of multiple semantic activation of the homophone, the present experiment assessed picture-word interference at intervals of 0 and $+100 \mathrm{msec}$ between picture and word onset.

\section{METHOD}

\section{Subjects}

One hundred four Rice University undergraduate students participated as part of a class requirement; 52 of them were randomly assigned to each SOA group.

\section{Materials}

Twenty-four semantically unrelated homophonous word pairs were selected. Twenty-four line drawings from the Snodgrass and Vanderwart (1980) set were chosen as targets that were semantic coordinates to one of the members of each homophone word pair. Finally, 24 semantically unrelated words were selected (see the Appendix for a listing). To control for potential graphemic effects, distractor words in the unrelated condition were matched to the homophonous distractor words in terms of orthographic overlap with the semantic coordinates
The experimental material was counterbalanced across subjects so that each subject saw 12 targets paired with the semantically related distractor, the other 12 targets paired with the distractors homophonically related to the semantic distractor, and each target paired with the unrelated distractors. In addition, each target picture was shown six times with other, unrelated distractors, which served as fillers. This resulted in a total of 192 responses for each subject, with each target picture named eight times by each subject. These trials were shown to each subject in one of six pseudorandom sequences such that each picture was never followed by the same picture.

\section{Procedure and Apparatus}

All stimuli were presented and response latencies were taken from an Apple PowerPC computer using PsyScope (Cohen, MacWhinney, Flatt, \& Provost, 1993). Naming responses were measured by means of a voice-activated relay to the nearest millisecond. The pictures were presented with a size of approximately $3 \times 3$ in. as black line drawings on white background. Distractor words were presented in uppercase Helvetica 14 bold font in the center of each picture, either simultaneously with the onset of the picture (SOA $=0 \mathrm{msec}$ ) or $100 \mathrm{msec}$ after picture onset $(\mathrm{SOA}=+100 \mathrm{msec})$. Both target picture and distractor word remained on the screen until the participant made a vocal response. After each response, the experimenter indicated either a correct response or an incorrect response/voice-key malfunction by typing a code into the computer. Each trial was concluded with an intertrial interval of $1,500 \mathrm{msec}$.

The subjects were instructed to name line drawings of objects presented on the screen as fast and accurately as possible. To familiarize them with the target pictures prior to the experimental trials, these drawings were presented one by one on the screen with the correct picture label written below it. Subsequently, 24 practice trials were presented in which each target picture was shown with an unrelated distractor and subjects were asked to name the picture. After that, the 192 experimental trials were presented with a resting period after the first half of the trials. Each experimental session lasted approximately $30 \mathrm{~min}$.

\section{RESULTS}

Trials in which subjects gave incorrect responses, produced repairs, or stuttered and trials in which the voice key malfunctioned were excluded from the analysis $(2.9 \%)$.

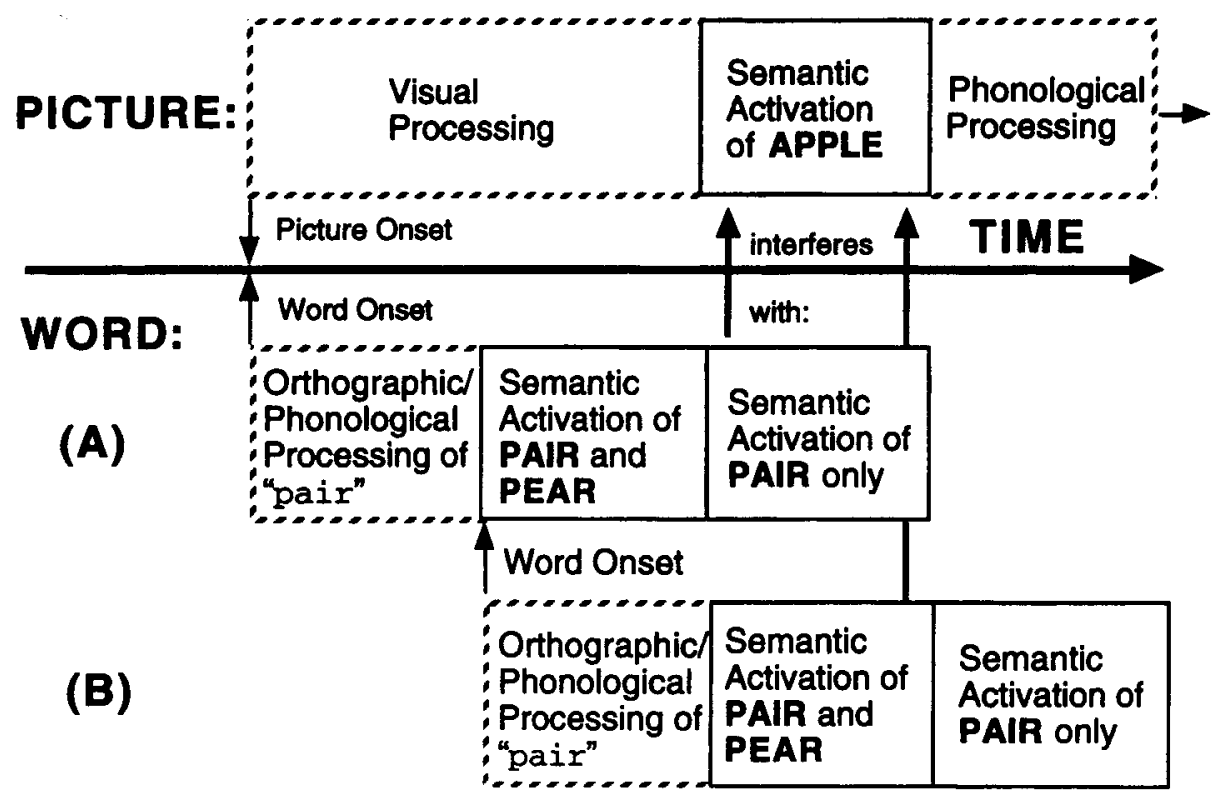

Figure 1. Semantic activation of picture names and word distractors relative to picture-word SOA. (A) SOA = 0 msec; (B) SOA $=+100$ msec. 
Table 1

Mean Response Latencies (in Milliseconds) for Target Pictures With Semantically and Homophonically Related Distractors and Their Control Items

\begin{tabular}{ccc}
\hline & \multicolumn{2}{c}{ Target-Distractor Relationship } \\
\cline { 2 - 3 } Condition & Semantic & Homophone \\
\hline SOA = 0 msec & & \\
Related & 784 & 755 \\
Unrelated & 760 & 766 \\
Effect & $-24^{*}$ & 11 \\
SOA = +100 msec & & \\
Related & 762 & 751 \\
Unrelated & 757 & 755 \\
Effect & 5 & 4 \\
\hline
\end{tabular}

${ }^{*} p<.05$.

Furthermore, responses that exceeded a subject's conditional mean by more than $2 S D$ s were excluded $(4.8 \%)$. Table 1 displays the mean naming latencies by distractor type.

For an SOA of 0 msec, the means indicate the expected interference effect for semantically related distractors, but no effect of homophonically related distractors. For an SOA of $+100 \mathrm{msec}$, the results suggest no effect of either type of distractor. An analysis of variance conducted on the results indicated a significant main effect of type of distractor $\left[F_{1}(1,102)=5.16, p=.025\right]$ that was insignificant in the items analysis $\left[F_{2}(1,46)=1.04, p>.1\right]$. The main effect of relatedness as well as the main effect of SOA were not significant $\left(F_{1}=0.60, F_{2}=0.39\right.$, and $F_{1}=0.31, F_{2}=1.80$, respectively). A significant type of distractor $\times$ relatedness interaction was obtained $\left[F_{1}(1,102)=4.14, p=.044 ; F_{2}(1,92)=5.00, p=.028\right]$. All other interactions were not significant.

Planned comparisons of means indicated that, for an SOA of 0 msec, the effect of semantically and homophonically related distractors differed significantly from each other $\left[t_{1}(51)=2.65, p=.011 ; t_{2}(23)=2.63, p=.012\right]$. The 24-msec interference for semantically related distractors was significantly different from zero $\left[t_{1}(51)=2.57\right.$, $\left.p=.013 ; t_{2}(23)=2.36, p=.027\right]$, whereas the effect for homophonically related distractors was not $\left[t_{1}(51)=\right.$ $\left.1.39, t_{2}(23)=1.31\right]$. For an SOA of $+100 \mathrm{msec}$, the effects of semantically and homophonically related distractors did not differ from each other $(t<0.48)$, nor did either condition differ from zero (both $t \mathrm{~s}<0.40$ ). ${ }^{1}$

\section{DISCUSSION}

The results replicated the standard interference effect of semantically related distractors on picture-naming latencies, which is generally obtained with an SOA of $0 \mathrm{msec}$. In contrast, distractors homophonically related to the semantic picture coordinates yielded no suggestion of an interference effect at this SOA. ${ }^{2}$ These findings are not in accordance with the assumption that lexical access is necessarily mediated through phonological coding. The absence of a semantic interference effect with an SOA of $+100 \mathrm{msec}$ indicates that the visually presented distractor words have not yet accessed their semantic representations and suggests that this SOA taps into a stage of word processing prior to semantic access. To account for no interference at +100 -msec SOA and interference from only the semantically related distractor at 0 -msec SOA, proponents of the phonological theory of lexical access would have to claim that acti- vation of multiple meanings plus a subsequent spelling-check procedure occurred and was finished somewhere in between these two SOAs. This possibility, however, appears rather unlikely: Although Lukatela and Turvey's (1994a, 1994b) studies indicate a fairly rapid process, this procedure sets in at some point after the SOA of $100 \mathrm{msec}$ employed in their experiment, which yielded homophonic priming. The more plausible explanation for the present findings is that the role of phonological codes in lexical access in the picture-word interference paradigm is limited.

The present results add to a substantial number of findings failing to demonstrate an effect of phonology in visual lexical access. The discrepancy between experimental results that indicate phonological access and those which do not deserves an explanation. Conceivably, the activation of phonological codes might be under strategic control of the subject and responsive to procedural constraints, a possibility that has been raised relatively early (Davelaar et al., 1978). For instance, Perfetti et al. (1988), whose study indicated phonological access, used a backward masking procedure that is normally taken to reflect purely automatic processing. However, a recent study by Verstaen, Humphreys, Olson, and D'Ydewalle (1995), who used the same procedure, demonstrated that effects previously interpreted as showing automatic phonological access were sensitive to the utility for the task: Phonological effects were obtained only when these were beneficial for performance. Likewise, it might be argued that the word-naming task employed in Lesch and Pollatsek (1993) and Lukatela and Turvey (1994a, 1994b) generally favored the use of letter-sound conversion because of the need to generate a phonological code from print in order to perform the task. In contrast, in the picture-naming task employed in the present study, subjects had to access the name of the picture presumably after accessing its semantic representation (Schriefers, Meyer, \& Levelt, 1990) and were instructed to ignore the distractor words, which were presented in close temporal proximity to the pictures. Under these circumstances, any processing of the distractor words would be detrimental to picturenaming performance. Because there was no utility in activating the corresponding phonological codes of the distractors, the results failed to show interference from the homophonous distractors. The nature of such experimental set effects is admittedly not clearly specified yet and deserves more systematic investigation.

It should be noted that failures to find evidence for prelexical phonological coding in some tasks do not rule out the possibility that such coding is always occurring. That is, it is possible that processing via grapheme-phoneme conversion and via a direct visual route proceed simultaneously and automatically during reading. Task effects might demonstrate that the speed of processing in the different routes or the use of the output of the different routes is to some degree under strategic control of the subject (Milota et al., 1997). However, such a claim implies that processing via grapheme-phoneme conversion is always proceeding, although sometimes no evidence for it is obtained. To be confident of such a claim, one would have to find some means to tap into this slow, but automatic, process. In any event, the results do imply that access to meaning does not always proceed via a phonological code.

In conclusion, researchers claiming that visual lexical access is mandatorily mediated by phonological codes appear to make too strong a claim. The use of phonological codes to access meaning in singleword processing appears to be highly task dependent and subject to strategies in response to experimental constraints. At present, universal claims about the importance of phonological codes should be regarded with caution.

\section{REFERENCES}

Baluch, B., \& BeSNER, D. (1991). Visual word recognition: Evidence for strategic control of lexical and nonlexical routines in oral reading. Journal of Experimental Psychology: Learning, Memory, \& Cognition, 17, 644-652.

Cohen, J., MacWhinney, B., Flatt, M., \& Provost, J. (1993). PsyScope: An interactive graphic system for designing and controlling experiments in the psychology laboratory using Macintosh computers. Behavioral Research Methods, Instruments, \& Computers, 25, 257-271.

Coltheart, M. (1980). Reading, phonological recoding and deep dyslexia. In M. Coltheart, K. Patterson, \& J. C. Marshall (Eds.), Deep dyslexia (pp. 197-226). London: Routledge \& Kegan Paul. 
Coltheart, M., \& Coltheart, V. (1997). Reading comprehension is not exclusively reliant upon phonological representation. Cognitive Neuropsychology, 14, 167-175.

Davelaar, E., Coltheart, M., Besner, D., \& Jonasson, J. T. (1978). Phonological recoding and lexical access. Memory \& Cognition, 6 , 391-402.

GLASER, W. R., \& DÜNGELHOFF, F.-J. (1984). The time course of pictureword interference. Journal of Experimental Psychology: Human Perception \& Performance, 10, 640-654.

hawkins, H. C., Reicher, G. M., Rogers, M., \& Peterson, L. (1976). Flexible coding in word recognition. Journal of Experimental Psychology: Human Perception \& Performance, 2, 380-385.

Hudson, P. T., \& Bergman, M. W. (1985). Lexical knowledge in word recognition: Word length and word frequency in naming and lexical decision tasks. Journal of Memory \& Language, 24, 46-58.

Lesch, M. F., \& Pollatsek, A. (1993). Automatic access of semantic information by phonological codes in visual word recognition. Journal of Experimental Psychology: Learning, Memory, \& Cognition, 19, 285-294.

Lukatela, G., \& Turvey, M. T. (1994a). Visual lexical access is initially phonological: I. Evidence from associative priming by words, homophones, and pseudohomophones. Journal of Experimental Psychology: General, 123, 107-128.

LukATELA, G., \& TuRVEY, M. T. (1994b). Visual lexical access is initially phonological: 2 . Evidence from phonological priming by homophones and pseudohomophones. Journal of Experimental Psychology: General, 123, 331-353.

LUPKER, S. J. (1982). The role of phonetic and orthographic similarity in picture word interference. Canadian Journal of Psychology, 36, 349-367.

MarTIN, R. C. (1982). The pseudohomophone effect: The role of visual similarity in nonword decisions. Quarterly Journal of Experimental Psychology, 34A, 395-409.

MCQUADE, D. (1981). Variable reliance on phonological information in visual word recognition. Language \& Speech, 24, 99-109.

Meyer, D. E., Schvaneveldt, R. W., \& Ruddy, M. G. (1974). Functions of graphemic and phonemic codes in visual word-recognition Memory \& Cognition, 2, 309-321.

Milota, V. C., Widau, A. A., MCMickell, M. R., Juola, J. F., \& SimpSON, G. B. (1997). Strategic reliance on phonological mediation in lexical access. Memory \& Cognition, 25, 333-344.

Perfetti, C. A.. \& BelL, L. [C.] (1991). Phonemic activation during the first $40 \mathrm{~ms}$ of word identification: Evidence from backward masking and priming. Journal of Memory \& Language, 30, 473-485.

Perfetti, C. A., Bell, L. C., \& Delaney, S. M. (1988). Automatic (prelexical) phonetic activation in silent word reading: Evidence from backward masking. Journal of Memory \& Language, 27, 59-70.

Potter, M. C., \& Faulconer, B. A. (1975). Time to understand pictures and words. Nature, 253, 437-438.

RAYNER, K., \& POSNANSKY, C. (1978). Stages of processing in word identification. Journal of Experimental Psychology: General, 107, 64-80.

Rosinski, R. R., GolinKOFF, R. M., \& KUKISH, K. S. (1975). Automatic semantic processing in a picture-word interference task. Child Development, 46, 247-253.

Rubenstein, H., Lewis, S., \& Rubenstein, M. (1971). Evidence for phonemic recoding in visual word recognition. Journal of Verbal Learning \& Verbal Behavior, 10, 645-657.

SChriefers, H., Meyer, A. S., \& LeVelt, W. J. M. (1990). Exploring the time course of lexical access in language production: Picture-word interference studies. Journal of Memory \& Language, 29, 86-102.

SNodgrass, J. G., \& MCCullough, B. (1986). The role of visual similarity in picture categorization. Journal of Experimental Psychology: Learning, Memory, \& Cognition, 12, 147-154.

SNODGRASS, J. G., \& VANDERWART, M. (1980). A standardized set of 260 pictures: Norms for name agreement, image agreement, familiarity, and visual complexity. Journal of Experimental Psychology: $\mathrm{Hu}$ man Learning \& Memory, 6, 174-215.

StarkeVeld, P. A., \& La Heu, W. (1996). Time-course analysis of semantic and orthographic context effects in picture naming. Journal of Experimental Psychology: Leaming, Memory, \& Cognition, 22, 896-918.
TABOSSI, P., \& LAGHI, L. (1992). Semantic priming in the pronunciation of words in two writing systems: Italian and English. Memory \& Cognition, 20, 303-313.

VAN ORDEN, G. C. (1987). A ROWS is a ROSE: Spelling, sound, and reading. Memory \& Cognition, 15, 181-198.

Van Orden, G. C., Johnston, J. C., \& Hale, B. L. (1988). Word identification in reading proceeds from spelling to sound to meaning. Journal of Experimental Psychology: Learning, Memory, \& Cognition, 14, 371-386.

Verstaen, A., Humphreys, G. W., Olson, A., \& D'Ydewalle, G. (1995). Are phonemic effects in backward masking evidence for automatic prelexical phonemic activation in visual word recognition? Journal of Memory \& Language, 34, 335-356.

\section{NOTES}

1. An anonymous reviewer pointed out that a number of the homophonic distractors have irregular spelling-sound correspondences and that this irregularity might have slightly delayed lexical access, resulting in an absence of interference. However, an analysis of the results from only the regularly spelled distractors did not change the pattern of findings.

2. This experimental design, in which each picture is named repeatedly by each subject, is standard procedure in picture-word interference studies. However, the issue might be raised of whether repetition priming effects possibly obliterate interference effects caused by the distractors. An analysis that separated the data from each subject into two halves yielded no substantial difference in the amount of semantic interference at $\mathrm{SOA}=0 \mathrm{msec}$ in each half for the semantically related distractors $(-20 \mathrm{msec}$ for the first half and $-29 \mathrm{msec}$ for the second half). Also, there was no interference caused by homophonic distractors in either half at this SOA.

APPENDIX

Stimulus Material

\begin{tabular}{|c|c|c|c|}
\hline Target & $\begin{array}{c}\text { Semantic } \\
\text { Coordinate }\end{array}$ & Homophone & Unrelated \\
\hline APPLE & PLUM & PLUMB & PLUME \\
\hline BOTTLE & URN & EARN & TANK \\
\hline CAKE & BREAD & BRED & BREAST \\
\hline CANNON & ВOMB & BALM & BRIM \\
\hline CORN & LEEK & LEAK & PEEK \\
\hline CUP & PLATE & PLAIT & PLEA \\
\hline ESCALATOR & STAIRS & STARES & STAIN \\
\hline FLAG & POLE & POLL & MOLE \\
\hline FOOT & CLAWS & CLAUSE & CLAMP \\
\hline HAIR & FUR & FIR & FUSE \\
\hline HARP & LYRE & LIAR & LEAF \\
\hline MUSHROOM & CARROT & CARAT & CARP \\
\hline NECKLACE & RING & WRING & ROBIN \\
\hline OWL & PIGEON & PIDGIN & PIGLET \\
\hline PEANUT & KERNEL & COLONEL & LAUNCH \\
\hline PIG & BOAR & BORE & ROAM \\
\hline PITCHER & BOWL & BOLL & BOIL \\
\hline PLUG & CORD & CHORD & COBRA \\
\hline SAILBOAT & FERRY & FAIRY & FURY \\
\hline SAW & AXE & ACTS & ACID \\
\hline SEAL & WHALE & WAIL & WHEAT \\
\hline SPIDER & FLEA & FLEE & FLEX \\
\hline SWAN & FOWL & FOUL & FOAL \\
\hline TREE & FLOWER & FLOUR & PLOW \\
\hline
\end{tabular}

(Manuscript received March 24, 1997; revision accepted for publication August 18, 1997.) 